\title{
Inhibition of p53 Transcriptional Activity: A Potential Target for Future Development of Therapeutic Strategies for Primary Demyelination
}

\author{
Jiadong Li, ${ }^{1}$ Cristina A. Ghiani, ${ }^{2}$ Jin Young Kim, ${ }^{1}$ Aixiao Liu, ${ }^{1}$ Juan Sandoval, ${ }^{1}$ Jean DeVellis, ${ }^{2}$ and \\ Patrizia Casaccia-Bonnefil ${ }^{1}$ \\ ${ }^{1}$ Department of Neuroscience and Cell Biology, Robert Wood Johnson Medical School, Piscataway, New Jersey 08854, and ²Departments of Psychiatry and \\ Neurobiology, Mental Retardation Research Center, David Geffen School of Medicine, University of California, Los Angeles, Los Angeles, California 90095
}

\begin{abstract}
Oligodendrogliopathy, microglial infiltration, and lack of remyelination are detected in the brains of patients with multiple sclerosis and are accompanied by high levels of the transcription factor p53. In this study, we used the cuprizone model of demyelination, characterized by oligodendrogliopathy and microglial infiltration, to define the effect of $p 53$ inhibition. Myelin preservation, decreased microglial recruitment, and gene expression were observed in mice lacking $p 53$ or receiving systemic administration of the p 53 inhibitor pifithrin- $\alpha$, compared with untreated controls. Decreased levels of lypopolysaccharide-induced gene expression were also observed in vitro, in $p 53^{-1-}$ primary microglial cultures or in pifithrin- $\alpha$-treated microglial BV2 cells. An additional beneficial effect of lack or inhibition of $p 53$ was observed in Sox $2+$ multipotential progenitors of the subventricular zone that responded with increased proliferation and oligodendrogliogenesis. Based on these results, we propose transient inhibition of $p 53$ as a potential therapeutic target for demyelinating conditions primarily characterized by oligodendrogliopathy.
\end{abstract}

Key words: myelin repair; oligodendrocyte; microglia; transcription; myelin; demyelination

\section{Introduction}

Multiple sclerosis (MS) is a demyelinating disorder characterized by heterogeneity of clinical and neuropathological signs and disease susceptibility (Lucchinetti et al., 2000). At least two broad categories have been defined based on neuropathological findings: one is characterized by immune-mediated demyelination occurring at perivenous locations, whereas the other one is characterized primarily by myelin loss consequent to oligodendrogliopathy and is associated with extensive microglial infiltration (Barnett and Prineas, 2004). An additional difference between these two neuropathological findings is the presence of remyelination attempts that are frequently detected in the immunemediated forms and are less prominent in cases with extensive oligodendrogliopathy (Lucchinetti et al., 2000). Very little is known regarding the causes of oligodendroglial death in MS patients; however, increased levels of the pro-apoptotic transcription factor $p 53$ and of its downstream genes have been detected in cases characterized by oligodendrogliopathy, microglial infiltra-

\footnotetext{
Received Sept. 17, 2007; revised March 23, 2008; accepted April 29, 2008.

This work was supported by National Institutes of Health (NIH)-National Insitute of Neurological Disorders and Stroke Grant R01 NS052738, NIH-National Institute of Child Health and Human Development Grant P01 HD06576 and HD04612 (J.D.V.), National Multiple Sclerosis Society (P.C.-B.), the Christopher and Dana Reeve Foundation, and by the Multiple Sclerosis Research Foundation (P.C.-B.)

Correspondence should be addressed to Dr. Patrizia Casaccia-Bonnefil at her present address: Department of Neuroscience, Mount Sinai School of Medicine, One Gustave Levy Place, Box 1065, New York, NY 10069. E-mail: patrizia.casaccia@mssm.edu.

DOI:10.1523/JNEUROSCI.0184-08.2008

Copyright $\odot 2008$ Society for Neuroscience $\quad$ 0270-6474/08/286118-10\$15.00/0
}

tion, and relative lack of remyelination (Kuhlmann et al., 2002; Aboul-Enein et al., 2003; Wosik et al., 2003; Stadelmann et al., 2005). Studies in cultured human oligodendrocytes further identified p53 as a critical pro-apoptotic effector (Ladiwala et al., 1999; Wosik et al., 2003). We thereby hypothesized that this transcription factor could play a very important role in models of primary demyelination consequent to oligodendrocyte dystrophy.

To test this hypothesis, we have adopted the cuprizone model of toxic demyelination, which is characterized by oligodendrocyte apoptosis and microglial infiltration (Hiremath et al., 1998; Matsushima and Morell, 2001). In this model, a reproducible pattern of demyelination can be induced in the dorsal corpus callosum of C57BL/6 mice by administering a cuprizone diet for 6 weeks (Matsushima and Morell, 2001). After 3 weeks of continuous feeding, mature oligodendrocytes die by apoptosis, and this is associated with microglial infiltration in the absence of any breakage of the blood-brain barrier (Hiremath et al., 1998) and increased expression of microglial gene products (Morell et al., 1998; Jurevics et al., 2002). In this study, we demonstrate that elevated levels of $p 53$ can be detected in the corpus callosum of mice during the first $2-3$ weeks of cuprizone diet. Using genetic deletion and pharmacological inhibition of $p 53$, we demonstrate that this transcription factor modulates three prominent events characteristic of human and animal models of primary demyelination consequent to oligodendrogliopathy, including extensive oligodendrocytic apoptosis, microglial activation, and lack of remyelination. Thus, we propose the transient inhibition of $p 53$ 
Table 1. Sequences of primers for quantitative PCR

\begin{tabular}{|c|c|c|}
\hline Gene & Forward & Reverse \\
\hline BDNF & 5'-CCATAAGGACGCGGACTTGT-3' & 5'-AAGAGTAGAGGAGGCTCCAAAGG-3' \\
\hline B2-Microglobulin & $5^{\prime}$-GATACATACGCCTGCAGAGTTAAGC-3' & $5^{\prime}$-GATCACATGTCTCGATCCCAGTAG-3' \\
\hline CHKL3 & 5'-ACTATTTTGAAACCAGCAGCCTTT-3' & 5'-AGATCTGCCGGTTTCTCTTAGTCA-3' \\
\hline CGT & 5'-TGGTTGACATACTGGATCACTATACTA-3' & $5^{\prime}$-CGATCACAAATCCACACATATCATT-3' \\
\hline CNPase & 5'-TGGTGTCCGCTGATGCTTAC-3' & 5'-CCGCTCGTGGTTGGTATCAT-3' \\
\hline Gadd45 & 5' -ATTACGGTCGGCGTGTACGA-3' & 5'-CAGCAGGCACAGTACCACGTTA-3' \\
\hline GAPDH & 5'-ACCCAGAAGACTGTGGATGG-3' & $5^{\prime}$-CACATTGGGGGTAGGAACAC-3' \\
\hline Lysozyme & 5'-GTCACTGCTCAGGCCAAGGT-3' & 5'-TAGCCAGCCATTCCATTCCT-3' \\
\hline MSC-2 & $5^{\prime}$-GGGTACTACTGCACAGCAGACAAC-3' & 5'-GGAATTTTCACGGTGATGTTCA-3' \\
\hline p21 & 5'-GAGACAACGGCACACTTTGCT-3' & $5^{\prime}-{ }^{\prime} C A C A G G C A C C A T G T C C A A-3^{\prime}$ \\
\hline Sox2 & 5'-AACTTTTGTCCGAGACCGAGAA-3' & $5^{\prime}$-CCTCCGGGAAGCGTGTACT-3' \\
\hline$T c f 4$ & 5' -GTCCTCGCTGGTCAATGAAT-3' & 5'-CCCTTAAAGAGCCCTCCATC-3' \\
\hline$T N F \alpha$ & $5^{\prime}$-GCACCACCATCAAGGACTCAA-3' & 5'-TGCAGAACTCAGGAATGGACAT-3' \\
\hline p53 & $5^{\prime}$-CTCACTCCAGCTACCTGAAGA-3' & 5'-AGAGGCAGTCAGTCAGTCTGAGTCA-3' \\
\hline Mouse IL1 $\beta$ & 5'-GTGAATGCCACCTTTTGACA-3' & $5^{\prime}$-CAAAGGTTTGGAAGCAGCC-3' \\
\hline
\end{tabular}

(Harlan Teklad Certified LM-485, code $7012 \mathrm{CM}$ ), which was available ad libitum. Sham and cuprizone-treated C57BL/6J mice $(n=40)$ were killed weekly for the time-course study $(n=24)$; the remaining $16 \mathrm{C} 57 \mathrm{BL} / 6 \mathrm{~J}$, the $p 53^{+/+}(n=24)$, and $p 53^{-/-}$mice $(n=24)$ were maintained on the cuprizone diet for the specified time period or received additional treatment as indicated by the specific experimental paradigm. Mice were maintained in sterile pathogen-free conditions according to protocols approved by the Institutional Animal Care and Use Committee of Robert Wood Johnson Medical School/University of Medicine and Dentistry of New Jersey.

Pifithrin treatment in vivo. The first group of C57BL/6J mice was subject to DMSO $(n=7)$ or pifithrin- $\alpha(n=7)(2 \mathrm{mg} / \mathrm{kg}$ body weight, i.p.) injection every other day after mice were fed with $0.2 \%$ cuprizone diet for 2 weeks. After $10 \mathrm{~d}$

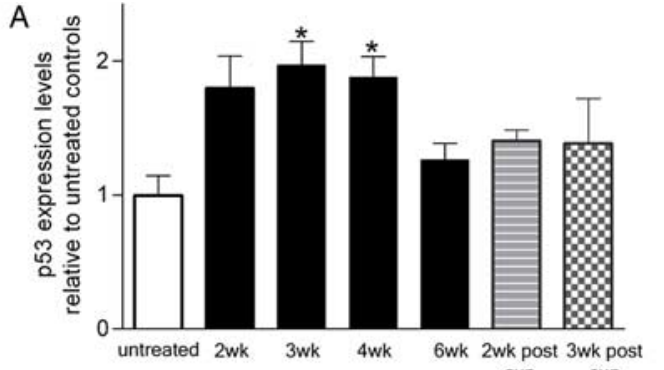
cup cup

B untreated p $53+/+$

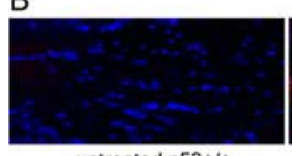

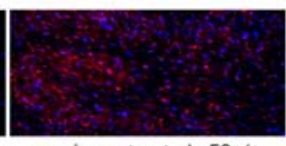

cuprizone treated $\mathrm{p} 53+1+$

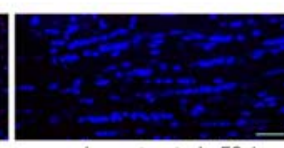

cuprizone treated $\mathrm{p} 53-\mathrm{-}$
Figure 1. Upregulation of $\mathrm{p} 53$ levels in the corpus callosum of mice on a cuprizone diet. $\boldsymbol{A}_{\boldsymbol{A}}$ Quantitative real-time PCR of p53 mRNA levels in samples isolated from the dorsal corpus callosum of mice treated with cuprizone for the indicated times (2wk, 3wk, 4wk, 6wk) and in mice treated with cuprizone and then allowed to recover for 2 or 3 weeks (2wk post cup, 3wk post cup). The levels were normalized to GAPDH, and the levels detected in mice that were fed a normal diet were arbitrarily set as reference point (untreated). Bar graphs represent the mean of at least four independent experiments, each performed in triplicate. Error bars indicate SEM. ${ }^{*} p<0.05$ (one-way ANOVA followed by Bonferroni's multiple comparison test). wk, Week; cup, cuprizone. $\boldsymbol{B}$, Immunohistochemistry of corpus callosum of untreated wild-type mice and cuprizone-treated wild-type ( $\mathrm{p} 53^{+/+}$) or $\mathrm{p} 53$ knock-out ( $\mathrm{p} 53^{-/-}$) mice stained with antibodies against p53 (red) and DAPI (blue). Staining of the sections from cuprizonetreated $p 53^{-I-}$ mice served as control for antibody specificity. Scale bar, $80 \mu \mathrm{m}$.

function as a potential therapeutic target for demyelinating conditions characterized by primary oligodendroglial dysfunction.

\section{Materials and Methods}

Animal model of experimental demyelination induced by dietary cuprizone. All of the experiments were performed in 8-week-old mice. For the experiments on $p 53$ expression levels and pifithrin- $\alpha$ treatment, we used C57BL/6J mice $(n=40)$. For the immunohistochemical experiments, the microarray gene expression profiling, and the validation by quantitative real-time PCR, we used mice obtained from $\operatorname{Tr} p 53^{\text {Tm1Tyj }}$ C57BL/6J heterozygous breeding pairs $\left(n=24 p 53^{+/+} ; n=24 p 53^{-/-}\right)$. Mouse genotypes were confirmed by tail clipping and PCR using the primers 5'-ACAGCGTGGTGGTACCTTAT-3 (ImRo36), 5' -TATACTCAGAGCCGGCCT-3' (ImRo37), and 5'-TCCTCGTGCTTTACGGTATC-3' (neo), yielding a fragment of $375 \mathrm{bp}$ for $p 53^{+/+}$and $525 \mathrm{bp}$ in $p 53^{-/-}$ mice. Eight-week-old male $p 53^{-/-}$and $p 53^{+/+}$sibling mice were placed on a diet of $0.2 \%(\mathrm{w} / \mathrm{w})$ cuprizone (Sigma) mixed into milled chow of continuous injection and feeding treatment, four mice were killed for perfusion with $4 \%$ paraformaldehyde (PFA) followed by cryopreservation and immunohistochemical analysis, and the remaining three mice were killed for RNA extraction. The second group of mice was subject to DMSO $(n=4)$ or pifithrin- $\alpha(n=4)(2 \mathrm{mg} / \mathrm{kg}$ body weight, i.p. $)$ injection every other day after mice were fed with $0.2 \%$ cuprizone diet for 4 weeks. After $10 \mathrm{~d}$ of continuous injection and feeding treatment, four mice were killed for perfusion with $4 \%$ PFA for immunohistochemical analysis.

Gene expression profiling using Affymetrix microarrays. Total RNA was isolated from whole brains of wild-type C57B mice or p53 knock-out mice after 4 weeks of cuprizone treatment using Trizol (Invitrogen) and cleaned up with the RNeasy Mini kit (Qiagen). RNA from each group $(n=3)$ was pooled in equimolar amount before hybridization with GeneChip Mouse Expression Set 430A Arrays (Affymetrix), which contains probes for detecting 22,600 transcripts. After RNA isolation, all the subsequent technical procedures including quality control, measurement of RNA concentration, cDNA synthesis, biotin labeling of cRNA, hybridization, and scanning of the arrays were performed using standard procedure at the Cancer Institute of New Jersey.

Quantitative real-time PCR. Total RNA was extracted from mouse brains by using Trizol reagent (Invitrogen) and cleaned using the RNeasy Mini kit (Qiagen). RNA quality was assessed by electrophoresis on denaturing MOPS (4-morpholinepropanesulfonic acid) gels and spectrophotometry. Two micrograms of total RNA were used in $20 \mu \mathrm{l}$ of reverse transcription (RT) reaction, using the SuperScript RT-PCR kit (Invitrogen). Quantitative real-time PCR was performed using Applied Biosystems SYBR green PCR master mix in the 7900HT Sequence Detection PCR System. Negative controls (samples in which reverse transcriptase was omitted) were amplified individually by PCR using the different primer sets used in the present studies to ensure the absence of genomic DNA contamination. PCR amplification resulted in the generation of single bands. The melting curve of each sample was measured to ensure the specificity of the amplified products. Data were normalized to the internal control glyceraldehyde-3-phosphate dehydrogenase (GAPDH) and analyzed using Pfaffl $\Delta \Delta \mathrm{Ct}$ method. For primers used in quantitative PCR, see Table 1.

Statistical analysis was performed using GraphPad Prism 4.01 software (Graph Pad Software) by ANOVA followed by Bonferroni's multiple comparison test or Friedman test, followed by Dunn's multiplecomparison test. An unpaired Student's $t$ test was used when only two conditions were compared.

Immunohistochemistry, confocal image acquisition, and quantitative analysis. For immunohistochemistry, animals were anesthetized and perfused intracardially with $4 \%$ PFA in $0.1 \mathrm{~m}$ phosphate buffer, $\mathrm{pH}$ 7.2. Weil myelin staining was performed by the histopathology service NeuroScience Associates. For all the other experiments, the brains were removed, postfixed overnight in the same solution at $4^{\circ} \mathrm{C}$, cryopreserved in $30 \%$ sucrose in $0.1 \mathrm{~m}$ phosphate buffer, and embedded in optimal cutting 
temperature compound. Frozen sections $(20 \mu \mathrm{m})$ were cut, incubated in blocking buffer PGBA ( $0.1 \mathrm{~m}$ phosphate buffer, $0.1 \%$ gelatin, $1 \%$ bovine serum albumin, $0.002 \%$ sodium azide) containing $10 \%$ normal goat serum $(0.5 \%$ Triton X-100 was added for cytoplasmic and nuclear antigens) for $30 \mathrm{~min}$, and incubated overnight with the primary antibody diluted in the same blocking buffer. After rinsing in PBS, sections were incubated with the appropriate secondary antibodies conjugated to fluorescein or rhodamine (Southern Biotechnologies, GE Healthcare, Jackson ImmunoResearch, and Vector Laboratories). 4',6-Diamidino-2phenylindole (DAPI; 1:1000; Invitrogen) was used as a nuclear counterstain. Immunostained sections were analyzed using a fluorescent microscope (DMRA; Leica) followed by confocal analysis (LSM 510 meta confocal laser-scanning microscope; Carl Zeiss MicroImaging). Confocal images were captured at a $1 \mu \mathrm{m}$ interval, and stacks of six slices were typically used for the generation of the projections. For the quantification of the in vivo experiments, a minimum of three sections per mouse and three mice for each group were evaluated. The following primary antibodies were used: anti- $\beta$-tubulin III (1:500, clone Tuj1; Covance), antiGFAP (1:1000; Dako), anti-bromodeoxyuridine (BrdU; 1:200; Dako), Sox2 (1:1000; Millipore Bioscience Research Reagents), CC1/APC (mouse monoclonal, 1:50; Oncogene Research Products), myelin basic protein (MBP; mouse monoclonal SMI99, 1:1000 for immunohistochemistry and Western blot analysis; Sternberger Monoclonals), Mac1 (rat monoclonal, 1:100; Millipore Bioscience Research Reagents), and Ki67 (Abcam). After incubation with primary antibodies, the cells were stained with the appropriate secondary antibodies conjugated with fluorophores (Jackson ImmunoResearch) or with biotin (Vector Laboratories). To stain with anti-BrdU antibodies (1:200; Dako), the sections were treated with $2 \mathrm{~N} \mathrm{HCl}$ for $10 \mathrm{~min}$ at room temperature, followed by neutralization in $0.1 \mathrm{~m}$ borax, $\mathrm{pH} 8.6$, for $10 \mathrm{~min}$ at room temperature. After washing with $0.1 \mathrm{M}$ phosphate buffer, the cells were incubated with antiBrdU antibodies in PGBA containing $0.1 \%$ Triton X-100 for at least $3 \mathrm{~h}$ at room temperature. Then, the cells were incubated with appropriate secondary antibodies and DAPI. Immunoreactive cells were analyzed using a fluorescence microscope (Leica), and images were captured using a Hamamatsu CCD camera using the Image software.

In vitro experiments in primary cultures of microglial cells from $p 53^{+/+}$ and $p 53^{-1-}$ mice and in the BV2 microglial cell line. Postnatal day 1 cortices from $\mathrm{p} 53^{+/+}$and $\mathrm{p} 53^{-/-}$siblings were used for cell culture. Briefly, after removal of the meninges, cortical tissue was minced and dissociated by gentle trituration in NM10 medium (DMEM plus $10 \%$ FBS), using fire-polished Pasteur pipettes. Cells were plated into P75 tissue culture flasks coated with $10 \mathrm{ng} / \mathrm{ml}$ poly-D-lysine and cultured at $37^{\circ} \mathrm{C}$ in a humidified incubator with $10 \% \mathrm{CO}_{2}$ supplementation. The medium was changed every $2 \mathrm{~d}$. Three weeks later, cells were harvested by shaking at $37^{\circ} \mathrm{C}$ at $190 \mathrm{rpm}$ overnight. The collected cells were plated into uncoated $10 \mathrm{~cm}$ tissue culture dishes. Thirty minutes after plating, the floating cells were discarded by replacing the medium. The following day, cells were treated with $100 \mathrm{ng} / \mathrm{ml}$ lypopolysaccharide (LPS) for $6 \mathrm{~h}$, and the RNA was harvested for additional analysis. The immortalized microglia cell line, BV2, was donated by V. Bocchini (University of Perugia, Perugia, Italy); it was generated by infecting primary mouse microglia cultures with a v-raf/v-myc oncogene-carrying retrovirus (J2) (Blasi et al., 1990). BV2 cells were maintained in DMEM/F-12 containing 10\% FCS. Confluent cultures were passed by trypsinization. BV2 cells were cultured in DMEM/F-12 plus $10 \%$ FBS until $\sim 75 \%$ confluent. Pifithrin- $\alpha(20 \mu \mathrm{M})$ and/or LPS (100 $\mathrm{ng} / \mathrm{ml})$ were added at the same time, and cells were harvested in Trizol $6 \mathrm{~h}$ later. Control cells received the same volume of water or DMSO. Total RNA was extracted as reported above. Expression levels of the genes of interest were normalized to GAPDH levels.

In vitro experiments in multipotential neural precursors derived from the adult subventricular zone. Subventricular zones (SVZs) were dissected from 8-week-old C57BL/6J mice in Leibovitz's L-15 medium (Invitrogen). After digestion with papain (Sigma), cells were mechanically dissociated by pipetting and resuspended in complete medium consisting of DMEM/F-12 (Invitrogen) supplemented with B27 (Invitrogen), $25 \mathrm{~mm}$ glucose, $2 \mu \mathrm{g} / \mathrm{ml}$ heparin (Sigma), $20 \mathrm{ng} / \mathrm{ml}$ epidermal growth factor (EGF) and $10 \mathrm{ng} / \mathrm{ml} \mathrm{FGF.} \mathrm{An} \mathrm{equal} \mathrm{number} \mathrm{of} \mathrm{cells} \mathrm{was} \mathrm{plated} \mathrm{in} 48$-well
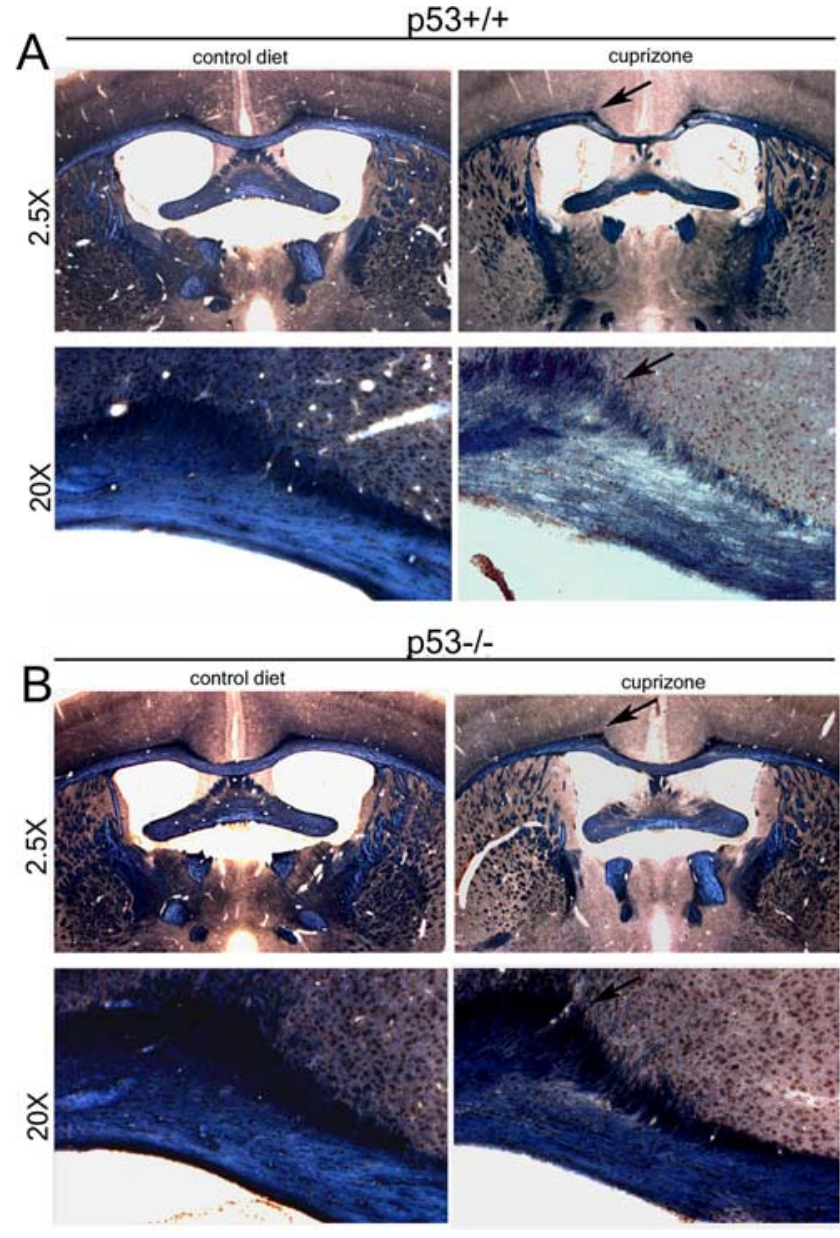

Figure 2. Mice lacking p53 are less sensitive to cuprizone-induced demyelination. $A$, Brightfield low-power $(2.5 \times)$ and high-power $(20 \times)$ micrographs of coronal brain sections of wild-

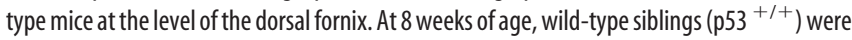
fed for 4 weeks with regular food (control diet) or with a modified diet containing $0.2 \%$ cuprizone and then killed. Brain sections were stained with Weil's to detect myelinating tracts. Note the reduction of myelinating fibers in the corpus callosum of cuprizone-treated wild-type mice (arrow). B, Low- and high-power micrographs of coronal brain sections from p53-deficient siblings ( $\mathrm{p} 3^{-1-}$ ) either untreated (control diet) or treated with cuprizone. Note the sparing of myelin in the corpus callosum of cuprizone-treated mice (arrow).

plates. Cells were incubated at $37^{\circ} \mathrm{C}$ in a $5 \% \mathrm{CO}_{2}$ incubator for $7 \mathrm{~d}$ and added fresh EGF (Peprotec) and FGF (Peprotec) every other day. To test multipotency of neural precursors in vitro, neurospheres were rinsed in $0.1 \mathrm{M}$ phosphate buffer and mechanically dissociated. The same number of cells was plated in 8-well chamber slides in differentiation medium: DMEM/F-12 supplemented with B27, 25 mM glucose, and 1\% FBS (Invitrogen). The following day, cells were pretreated with $25 \mu \mathrm{M}$ cuprizone (Sigma) for $24 \mathrm{~h}$ and allowed to differentiate for 5 additional days in differentiation medium in the presence or absence of $20 \mu \mathrm{M}$ pifithrin- $\alpha$.

\section{Results}

p53 is expressed in the corpus callosum of mice treated with cuprizone, and its ablation and pharmacological inhibition decrease the extent of demyelination

Elevated levels of the transcription factor p53 were previously described in the brain of MS patients characterized by demyelination consequent to oligodendroglial cell death and by microglial infiltration (Kuhlmann et al., 2002; Wosik et al., 2003). The animal model that best recapitulates these neuropathological findings is the cuprizone model of demyelination that is characterized by loss of myelin in the dorsal corpus callosum because of 

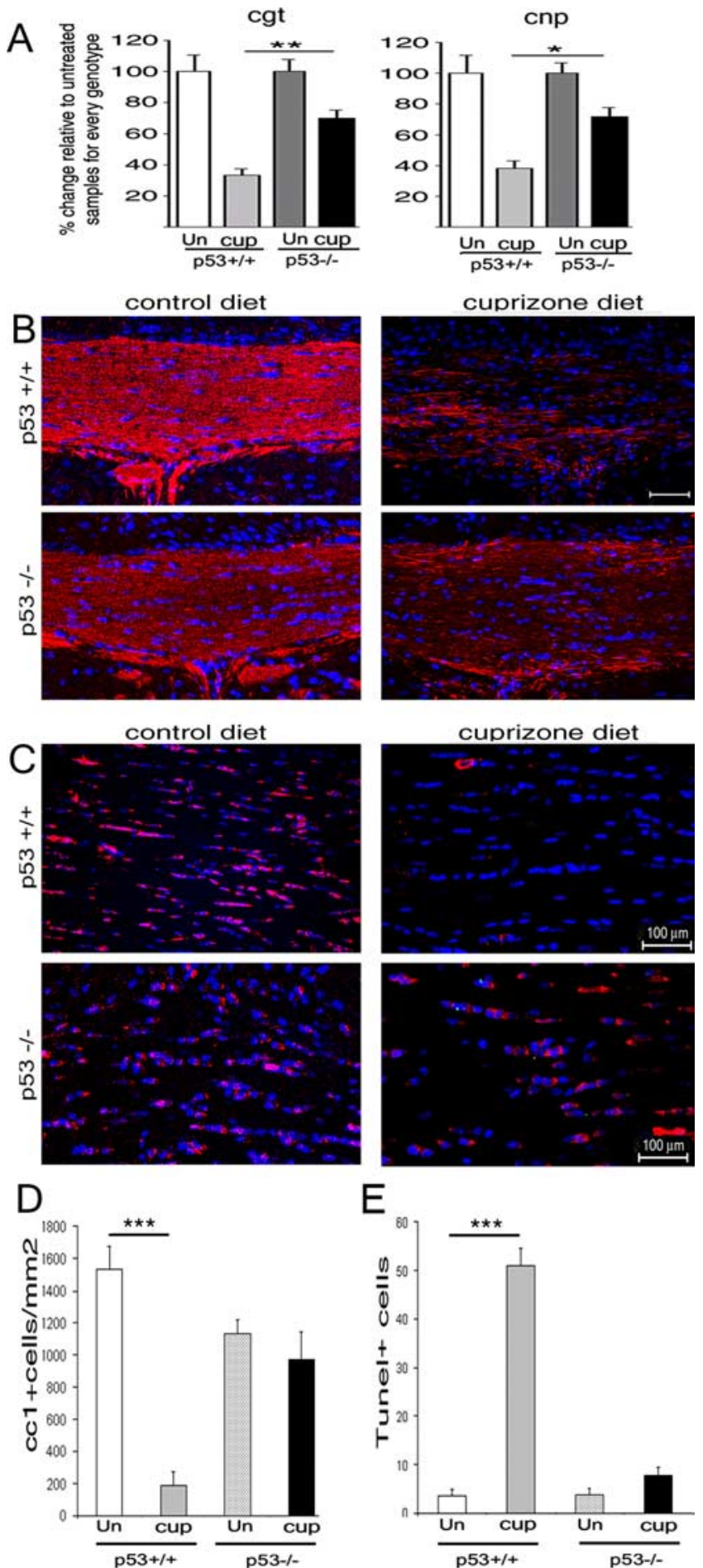

Figure 3. Increased oligodendrocyte survival and myelin sparing in mice lacking p53. $\boldsymbol{A}$, Relative RNA levels of the myelin gene transcripts for c $g$ t and cnp detected in the dorsal corpus callosum of $\mathrm{p} 3^{+/+}$and $\mathrm{p} 53^{-1-}$ mice after 4 weeks of feeding on a control or $0.2 \%$ cuprizone diet. The RNA levels in each sample were referred to the GAPDH levels, and the levels detected in the untreated animals were chosen as a reference point. Note the higher levels of myelin gene transcripts detected in cuprizone-treated $\mathrm{p} 53^{-1-}$ mice compared with treated wild-type siblings. ${ }^{*} p<0.05$; ${ }^{* *} p<0.01$. Error bars indicate SEM. $\boldsymbol{B}$, Confocal image of coronal brain sections of wild-type ( $p 53^{+/+}$) and knock-out ( $p 53^{-/-}$) siblings fed a control or cuprizone diet for 4 weeks and then stained with antibodies specific for MBP to identify myelinated fibers (red) and DAPI (blue) as nuclear counterstain. Scale bar, $50 \mu \mathrm{m}$. C, Confocal image of coronal brain sections of wild-type ( $\left.p 53^{+/+}\right)$and knock-out $\left(p 53^{-/-}\right)$siblings fed a control or a $0.2 \%$ cuprizone diet for 4 weeks and then stained with the $\mathrm{CC} 1$ antibody to identify oligodendrocytes (red) and DAPI (blue) as nuclear counterstain. D, Bar graphs indicate the relative number of $\mathrm{CC} 1+$ cells detected in the dorsal corpus callosum of $p 53^{+/+}$and $p 53^{-1-}$ mice oligodendrocytic death and microglial activation (Matsushima and Morell, 2001). To define whether p53 levels were also upregulated in the corpus callosum of cuprizone-fed mice, we performed real-time PCR on samples isolated at multiple time points during cuprizone treatment (Fig. 1A). In agreement with the previous findings in the brain of MS patients, in this animal model we also detected a twofold increase in $p 53$ transcripts during the first 2-3 weeks of cuprizone diet that temporally correlated with oligodendrocytic apoptosis and microglial infiltration (Matsushima and Morell, 2001). The increased transcripts were accompanied by enhanced immunoreactivity in the corpus callosum of cuprizone-treated mice in coronal sections stained with a commercially available antibody against p53, the specificity of which was supported by the inability to stain sections from knock-out mice (Fig. $1 B$ ). Based on these results, we hypothesized that $\mathrm{p} 53$ may play an important role in the cuprizone model of demyelination.

To test this hypothesis, we compared the extent of myelin loss in the dorsal corpus callosum of $p 53^{+/+}(n=4)$ and $p 53^{-1-}(n=$ 4) mice after 4 weeks of cuprizone treatment (Fig. 2). Myelin in the corpus callosum of $p 53^{+/+}$and $p 53^{-/-}$treated mice was detected by Weil staining. Loss of myelinated fibers was detected in the dorsal corpus callosum of cuprizone-treated $p 53^{+/+}$mice (Fig. $2 A$ ) but not in the same brain region of cuprizone-treated $p 53^{-1-}$ siblings (Fig. $2 B$ ). The myelin loss detected in $p 53^{+/+}$ mice $(n=3)$ after 4 weeks of cuprizone was consistent with the decreased levels of myelin transcripts assessed by real-time PCR (Fig. 3A). The levels of ceramide-galactosyl-transferase (cgt) were $66.6 \pm 4 \%$, and the levels of $2^{\prime}, 3^{\prime}$ cyclic nucleotide- $3^{\prime}$ phosphodiesterase (cnp) transcripts in cuprizone-treated $p 53^{+/+}$ mice were $61.8 \pm 5 \%$ lower than untreated controls. In contrast, in cuprizone-treated $p 53^{-1-}$ mice, the $c g t$ levels were only $31.2 \pm$ $5 \%$ lower, and those of $c n p$ were $28 \pm 6 \%$ lower than untreated controls (Fig. $3 A$ ). Additional results supporting the preservation of myelinated fibers in the corpus callosum of $p 53^{-1-}$ mice $(n=$ 3 ) was provided by immunohistochemical analysis of coronal sections stained by antibodies specific for MBP (Fig. 3B). The persistence of MBP staining correlated with the greater number of surviving $\mathrm{CC} 1+$ oligodendrocytes in the corpus callosum of cuprizone-treated $p 53^{-/-}$mice compared with wild-type mice $(n=3)$ (Fig. 3C,D). In agreement with the hypothesized role of p53 as a pro-apoptotic gene, decreased apoptosis was detected in the corpus callosum of cuprizone-treated $p 53^{-1-}$ mice compared with $p 53^{+/+}$mice (Fig. $3 E$ ). Together, these data suggested an important role for $p 53$ function in myelin loss consequent to oligodendrogliopathy.

To further explore the potential therapeutic value of these findings, we asked whether pharmacological inhibition of $p 53$ with pifithrin- $\alpha$ (Culmsee et al., 2001) would similarly prevent myelin loss in the cuprizone model of demyelination. We adopted two distinct protocols of pifithrin- $\alpha$ administration. In a first set of experiments, wild-type C57BL/6 mice $(n=8)$ received systemic administration of pifithrin- $\alpha(2 \mathrm{mg} / \mathrm{kg}$ body weight; $n=$ 4 ) or vehicle control $(n=4)$ during the second and third week of

\section{$\leftarrow$}

receiving either control or $0.2 \%$ cuprizone diet. $n=3$ animals per condition; ${ }^{* * *} p<0.001 . \boldsymbol{E}$, Bar graphs indicate the relative number of TUNEL + cells detected in the dorsal corpus callosum of $p 53^{+/+}$and $p 53^{-1-}$ mice after 3 weeks of control or $0.2 \%$ cuprizone diet. $n=3$ animals per condition; ${ }^{* * *} p<0.001$. Note that in $p 53^{-1-}$ mice the difference in the number of $\mathrm{CC} 1+$ and TUNEL + cells between the untreated and cuprizone-treated groups is not statistically significant. Un, Untreated (control); cup, cuprizone; TUNEL, terminal deoxynucleotidyl transferase-mediated biotinylated UTP nick end labeling. 
cuprizone diet, at a time coincident with the detection of elevated p53 levels and peak of oligodendrocytic apoptosis in the corpus callosum (Fig. $4 A$ ). In a second set of experiments, pifithrin- $\alpha(n=4)$ or vehicle control $(n=4)$ was administered after the peak of oligodendrocytic death, during the fourth and fifth week of cuprizone treatment (Fig. 4D). Early administration of pifithrin- $\alpha$ significantly increased oligodendrocyte survival (Fig. 4B) while decreasing the number of apoptotic cells (Fig. $4 C$ ) detected in the corpus callosum. In contrast, late administration of pifithrin- $\alpha$ had a less prominent effect on oligodendrocyte survival (Fig. $4 F$ ), although it still protected the existing myelinated fibers (Fig. $4 E$ ). These results suggested that, besides the role in oligodendrocyte apoptosis, p53 might affect the integrity of myelinated fibers also by a second mechanism, possibly involving the activation of microglial cells recruited to the corpus callosum.

\section{Genetic and pharmacological inhibition} of p53 function decreases microglial recruitment and gene expression In agreement with the protective role of $p 53$ inhibition, gene expression profiling of samples isolated from the corpus callosum of $p 53^{+/+}$and $p 53^{-/-}$mice using Affymetrix gene microarrays revealed greater levels of myelin gene transcripts (supplemental Table 1, available at www. jneurosci.org as supplemental material) and lower levels of activated microglial gene transcripts (supplemental Table 2, available at www.jneurosci.org as supplemental material), in cuprizonetreated $p 53^{-/-}$compared with $p 53^{+/+}$mice. As expected, cuprizone-treated $p 53^{-1-}$ mice did not exhibit the characteristic upregulation of p53-dependent target genes (i.e., p21, gadd45) detected in treated $p 53^{+/+}$mice (Fig. $5 A$ ). Previous studies had reported the characteristic upregulation of microglial genes, including lysozyme, $\beta 2$-microglobulin, and several cathepsins in the corpus callosum of cuprizone-fed mice (Morell et al., 1998; Jurevics et al., 2002). In agreement with the hypothesis that p53 function interferes with the program of microglial gene activation, we detected lower levels of lysozyme, $\beta 2$-microglobulin, and tnf $\alpha$ in the corpus callosum of cuprizone-treated $p 53^{-1-}$ mice compared with $p 53^{+/+}$mice (Fig. $5 B$ ). Similar results were obtained in mice receiving systemic administration of pifithrin- $\alpha$ because systemic administration of this inhibitor significantly impaired the cuprizone-induced upregulation of $p 21$ and gadd45 transcripts in cuprizone-fed mice (Fig. 5C) and lowered the transcriptional activation of microglia in response to cuprizone (Fig. 5D).

Decreased expression of genes characteristic of activated microglia in $p 53^{-1-}$ mice could result from impaired recruitment of microglial cells to the corpus callosum of cuprizone-fed mice and/or from a transcriptional effect of p53 in the recruited microglial cells. The presence of microglial cells was first assessed in the corpus callosum of cuprizone-fed $p 53^{-1-}$ mice using immunohistochemistry and antibodies specific for the antigen Mac1.
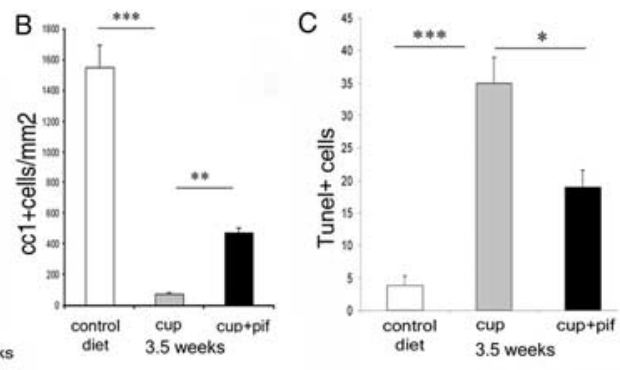

Figure 4. Systemic administration of pharmacological inhibitors of $\mathrm{p} 53$ is most effective in protecting oligodendrocytes and 列

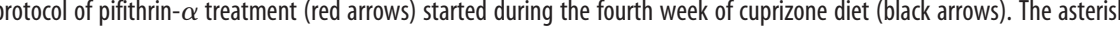
weeks in the absence (cup) or presence of systemic pifithrin- $\alpha$ (cup + pif) administration during the fourth week. $n=3$ for each treatment; ${ }^{* *} p<0.001 ;{ }^{* *} p<0.01$. Error bars indicate SEM. pif, Pifithrin- $\alpha$; cup, cuprizone.

Fewer Mac1 + cells were detected in the corpus callosum of cuprizone-treated $p 53^{-1-}$ mice compared with $p 53^{+/+}$mice (Fig. 6A,B). Similar results were detected in mice receiving pifithrin- $\alpha$ treatment either before (Fig. $6 C$ ) or after the occurrence of oligodendroglial death (Fig. 6D,E). When pifithrin- $\alpha$ treatment was started during the early stages of cuprizone diet, we observed a decline in oligodendrocytic apoptosis and the nearly complete absence of $\mathrm{Macl}+$ cells in the corpus callosum of treated animals (Fig. 6C). This effect could be attributable to the fact that fewer microglial cells were recruited to the corpus callosum if fewer oligodendrocytes died. In a second set of experiments, pifithrin- $\alpha$ treatment was initiated after the period of massive oligodendrocytic death had already occurred. Also in this case, however, pifithrin- $\alpha$-treated mice showed a significantly reduced number of $\mathrm{Macl}^{+}$-immunoreactive cells in the corpus callosum (Fig. 6D). Together, these results suggest that modulation of $p 53$ function affects the behavior of microglial cells in multiple ways.

To further define whether the effect of p53 inhibition on microglial cells was cell intrinsic and independent of cross talks with the oligodendrocytic population, we adopted a reductionist approach and used either the BV2 microglial cell line or primary microglial cultures isolated from the cortices of $p 53^{-1-}$ and $p 53^{+/+}$mice. The advantage of the in vitro experimental system is the possibility to evaluate the effect of p53 on microglial gene expression, using a homogeneous and controlled experimental 
A
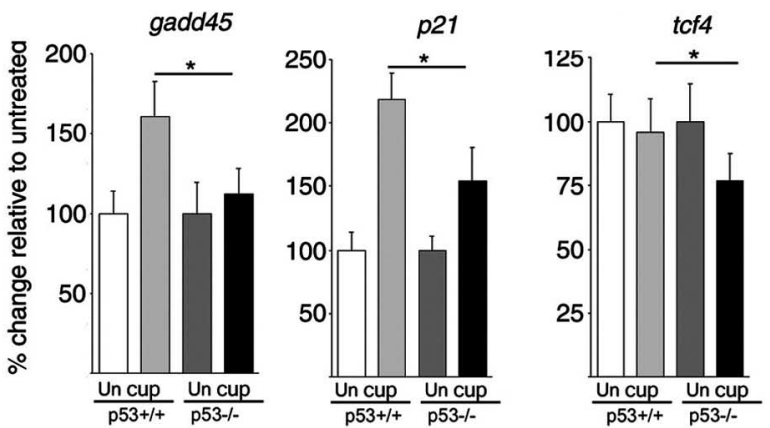

B
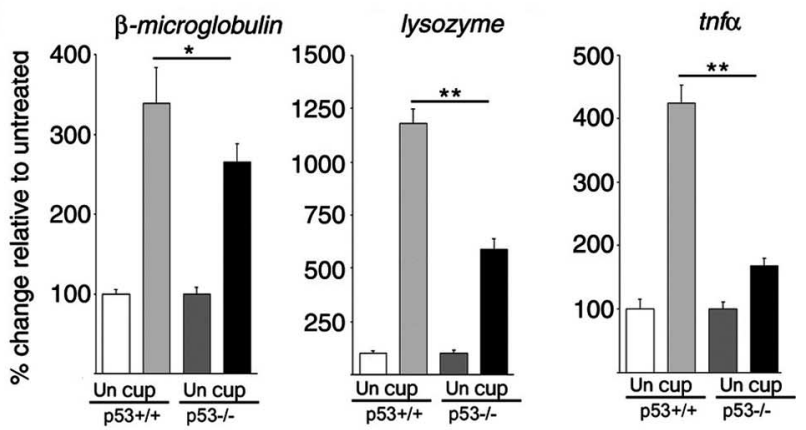

C
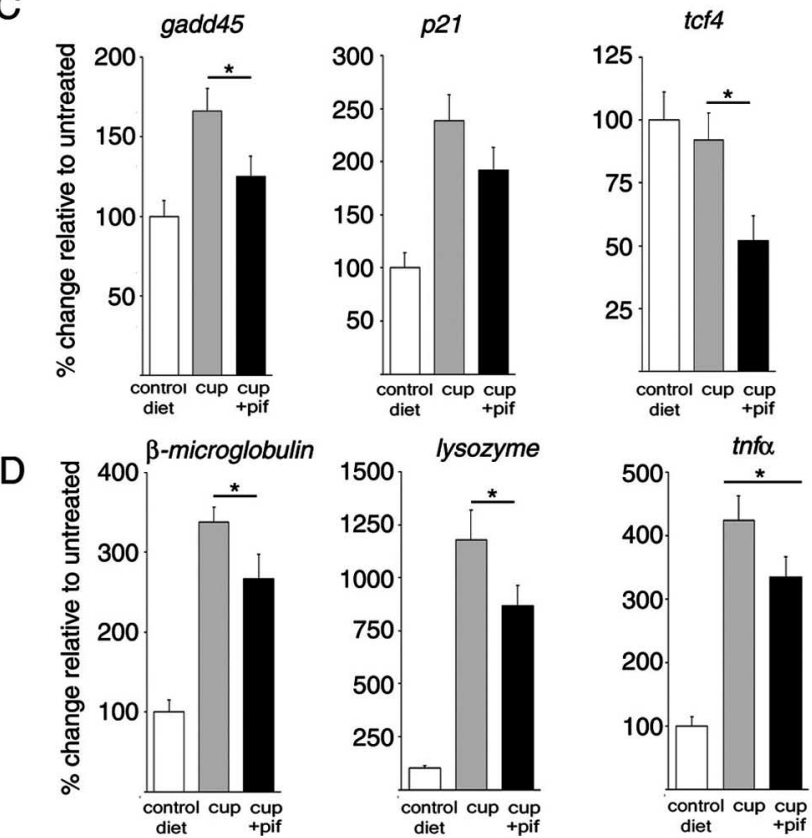

Figure 5. Decreased expression of microglial genes in mice with genetic deletion or pharmacological inhibition of $p 53 . A, B$, Quantitative real-time PCR of the mRNA levels for the $p 53$ target genes gadd45, p21, and tcf $4(\boldsymbol{A})$ and of $\beta 2$-microglobulin, lysozyme, and tnf- $\alpha(\boldsymbol{B})$ in samples isolated from the corpus callosum of untreated (un) and cuprizone-treated (cup) $p 53^{+/+}$and $p 53^{-/-}$mice. C, D, Quantitative real-time PCR of the mRNA levels for the $p 53$ target genes gadd45, p21, and tcf4 (C) and of $\beta 2$-microglobulin, lysozyme, and tnf- $\alpha(\boldsymbol{D})$ in samples isolated from the corpus callosum of untreated controls (control diet), cuprizone-fed mice (cup), and cuprizone-fed mice receiving pifithrin- $\alpha$ treatment (cup + pif). The RNA levels were referred to the GAPDH levels, and the values detected in cuprizone-treated mice in the absence and presence of pifithrin treatment were referred in terms of percentage value relative to the levels detected in untreated controls. ${ }^{*} p<0.05 ;{ }^{* *} p<0.01$. Error bars indicate SEM.

setting. Consistent with the possibility that p53 modulated the expression of genes characteristic of activated microglia, we detected increased $p 53$ levels in cultured microglial BV2 cells after LPS (100 ng/ml) stimulation (Fig. 7A). LPS also induced the expression of the p53 gene target $p 21$, and this increase was blocked by cotreatment with pifithrin- $\alpha(20 \mu \mathrm{M})$ (Fig. 7B). The LPS-dependent elevation of p21 transcript levels was also detected in $p 53^{+/+}$primary cultures of microglial cells from mice, but not in cells isolated from $p 53^{-1-}$ mice (Fig. 7C). Treatment of BV2 cells with pifithrin- $\alpha$ effectively reduced the LPS-dependent activation of the microglial genes lysozyme and $\beta 2$-microglobulin, although it had no effect on the levels of cathepsin $Z$ (Fig. 7D). Similarly, LPS stimulation or cuprizone treatment (supplemental Fig. 1, available at www.jneurosci.org as supplemental material) of primary microglial cultures elicited a greater increase in the transcript levels of $\beta 2$-microglobulin and $\operatorname{tnf} \alpha$ in $p 53^{+/+}$cells compared with $p 53^{-1-}$ mice (Fig. $7 E$ ). The fact that pifithrin or genetic ablation of $p 53$ did not completely abolish the transcriptional response of microglia to LPS is consistent with the importance of nuclear factor- $\kappa \mathrm{b}(\mathrm{NF}-\kappa \mathrm{b})$ regulation of this transcriptional program (Lu et al., 2007). Together, these data support a role for p53 as one of the modulators of gene expression in activated microglial cells.

We have previously mentioned that primary demyelination consequent to oligodendrogliopathy and microglial infiltration is also associated with defective repair. Because $p 53$ affected both oligodendrocyte loss and microglial activation, we asked whether this molecule could also modulate the behavior of cells affecting repair. Previous studies had shown that demyelination of the corpus callosum is repaired by resident oligodendrocyte progenitors and by multipotential cells residing in the adult SVZ (NaitOumesmar et al., 1999; Picard-Riera et al., 2002; Murtie et al., 2005; Trebst et al., 2007). Other studies (Billon et al., 2004), including those from our group (Gil-Perotin et al., 2006), had reported an important role for $p 53$ in regulating the pool of oligodendrocyte progenitors in the developing brain and in modulating the behavior of multipotential cells in the adult SVZ. However, the potential role of $p 53$ in repair after demyelination remained to be defined. To address this question, we tested p53 expression in the SVZ of cuprizone-treated mice (supplemental Fig. 2, available at www.jneurosci.org as supplemental material) and compared the responsiveness of multipotential SVZ cells in $p 53^{+/+}$mice with that observed in $p 53^{-/-}$and also in pifithrintreated $p 53^{+/+}$mice after cuprizone-induced demyelination. Immunohistochemical analysis of coronal brain sections using antibodies specific for the neural stem cell marker Sox 2 (Kondo and Raff, 2004) revealed an increase in immunoreactive cells in response to cuprizone-induced demyelination, a response that was enhanced by pifithrin-treated mice (Fig. $8 \mathrm{~A}$ ). In agreement with previous reports on the role of $\mathrm{p} 53$ in multipotential progenitors of the adult SVZ (Gil-Perotin et al., 2006), $p 53^{-1-}$ mice had greater resting numbers of Sox $2+$ cells, and cuprizone treatment significantly increased their number (Fig. 8 B). Because SVZ cells can be also characterized for the presence of the oligodendrocyte precursor surface molecule polysialic acid-neural cell adhesion molecule (PSA-NCAM) (Ben-Hur et al., 1998; Nait-Oumesmar et al., 1999, 2007; Decker et al., 2000), we conducted a similar analysis on the adult SVZ of cuprizone-treated mice. Consistent with the results obtained for Sox2, cuprizone treatment per se induced a significant increase in PSA-NCAM+ cells in the SVZ of untreated $\mathrm{p} 53^{+/+}$mice (Fig. $8 C$ ). This increase was further enhanced by either treatment with pharmacological inhibitors of p53 (Fig. 8C) or in animals with genetic ablation (Fig. 8D). Overall, these results suggest that p53 function is important for regulating the number of multipotential progenitors in the SVZ that are involved in repair.

Because p53 is an important modulator of the cell cycle, we asked whether the increased number of Sox $2+$ cells was attribut- 
able to increased proliferation and possibly altered differentiation of SVZ cells. Pifithrin- $\alpha$ treatment increased the number of proliferating cells in vivo, as assessed by the increased number of Ki67 + cells in the SVZ (Fig. 9A), similar to what previously reported for the characterization of the $p 53$ deficient mice (Gil-Perotin et al., 2006). To further define whether the effect on the multipotential progenitors was direct or mediated by other cell types, we dissected cells from the adult SVZ of $p 53^{-1-}$ and $p 53^{+/+}$mice (Fig. 9B), cultured them as neurospheres, and allowed them to differentiate into distinct lineages in cuprizonecontaining medium. Consistent with an inhibitory role of $p 53$ in oligodendrogliogenesis, we detected increased generation of oligodendrocytes and reduced generation of astrocytes in $p 53^{-1-}$ cultures, as described previously (Gil-Perotin et al., 2006). The experiment was then repeated with SVZ cells isolated from wild-type animals and treated with cuprizone and pifithrin- $\alpha$, to mimic the in vivo condition (Fig. 9C). Also in this case, p53 inhibition favored oligodendrogliogenesis at the expenses of astrocyte generation (Fig. 9D).

Based on these cumulative results, we suggest that transient $p 53$ inhibition should be further explored for the development of attractive therapeutic target for demyelinating conditions characterized by primary demyelination.

\section{Discussion}

The transcription factor p53 is a well characterized molecule with the ability to induce cell-cycle arrest and apoptosis in several cell types, in response to a wide variety of toxic stimuli (Giaccia and Kastan, 1998). Previous studies had identified p53 gene polymorphism in patients with MS (Kuhlmann et al., 2002) and reported high levels of protein expression in the brain of patients with demyelinated lesions characterized by extensive oligodendrogliopathy and lack of remyelination (Wosik et al., 2003). In this study, we define the functional significance of p53 inhibition using the cuprizone model of demyelination, characterized by oligodendrocytic apoptosis and microglial infiltration, the two neuropathological findings described in the brains of MS patients with elevated p53 levels. We also identify pifithrin- $\alpha$ as a promising novel therapeutic agent that reduces microglial activation and myelin loss, while stimulating the cells responsible for endogenous repair.

In addition to patients with specific forms of MS, p53 was also detected in the brain of patients with progressive multifocal leukoencephalopathy, where it was expressed at high levels in oligodendrocytes infected by the John Cunningham virus and undergoing apoptosis (Yang and Prayson, 2000). Studies in cultured
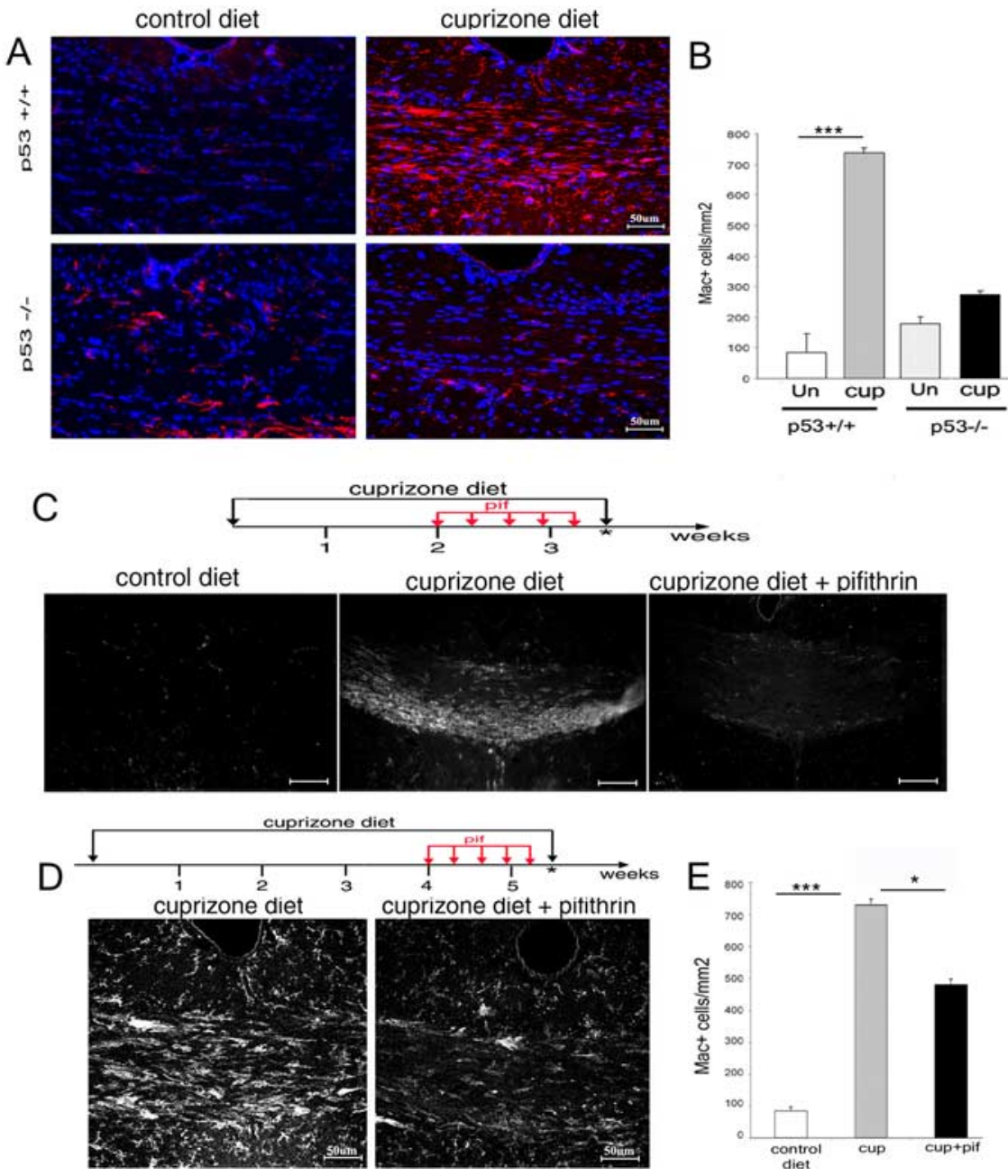

Figure 6. Pifithrin- $\alpha$ treatment of cuprizone-fed mice reduces recruitment of microglial cells to the corpus callosum even if initiated after oligodendrocyte apoptosis has occurred. $\boldsymbol{A}$, Confocal image of coronal brain sections of wild-type ( $\left.p 53^{+/+}\right)$and knock-out ( $p 53^{-1-}$ ) siblings fed either a control diet or a $0.2 \%$ cuprizone diet for 4 weeks and stained with Mac 1 antibody (red) to identify microglial cells and with DAPI (blue) as nuclear counterstain. $\boldsymbol{B}$, Bar graphs indicate the relative number of Mac1+ cells detected in the dorsal corpus callosum of $p 53^{+/+}$and $p 53^{-/-}$mice receiving either control (Un) or $0.2 \%$ cuprizone (cup) diet. $n=3$ animals per condition; ${ }^{* * *} p<0.001$. C, Schematic representation of the duration of the early pifithrin- $\alpha$ treatment (red arrows) in mice fed a cuprizone diet for 3.5 weeks (black arrows). The asterisk denotes the time point of analysis when the animals were killed and the brains were processed for immunohistochemistry (top). Immunohistochemistry of coronal brain sections of the medial corpus callosum at the level of the dorsal fornix, stained with antibodies specific for the microglial marker Mac1 (bottom), is shown. Note the presence of immunoreactive cells only in the cuprizone-fed mice but not in mice on a control diet or in mice treated with pifithrin- $\alpha$ during the first 3 weeks of cuprizone diet. Scale bars, $80 \mu \mathrm{m}$. D, Schematic representation of the duration of the late pifithrin- $\alpha$ treatment (red arrows) in mice fed a cuprizone diet for 5.5 weeks (black arrows). The asterisk denotes the time point of analysis when the animals were killed and the brains were processed for immunohistochemistry. Immunohistochemistry of coronal brain sections of the medial corpus callosum at the level of the dorsal fornix, of mice treated as described in $\boldsymbol{C}$, is shown. Sections were stained with antibodies specific for the microglial marker Mac1. $\boldsymbol{E}$, Bar graph representation of Mac1 + cells in the dorsal corpus callosum of animals that received either a control diet or a $0.2 \%$ cuprizone diet for 5.5 weeks in the absence (cup) or presence of systemic pifithrin- $\alpha$ (cup + pif) administration during the fourth week. $n=3$ for each treatment; ${ }^{* * *} p<0.001 ;{ }^{*} p<0.05$. Error bars indicate SEM. pif, Pifithrin- $\alpha$.

oligodendrocytes further defined this molecule as a downstream effector of pro-apoptotic pathways induced by tumor necrosis factor- $\alpha$ (Ladiwala et al., 1999), oxidative stress (Uberti et al., 1999), or glutamate agonists (Villapol et al., 2007). In agreement with the pro-apoptotic role of p53 in oligodendroglial apoptosis, we show here that $p 53^{-/-}$mice and mice receiving systemic administration of the $\mathrm{p} 53$ inhibitor pifithrin- $\alpha$ are less susceptible to cuprizone-induced demyelination and show enhanced oligodendrocytic survival.

We also describe a role for p53 in modulating the behavior of 


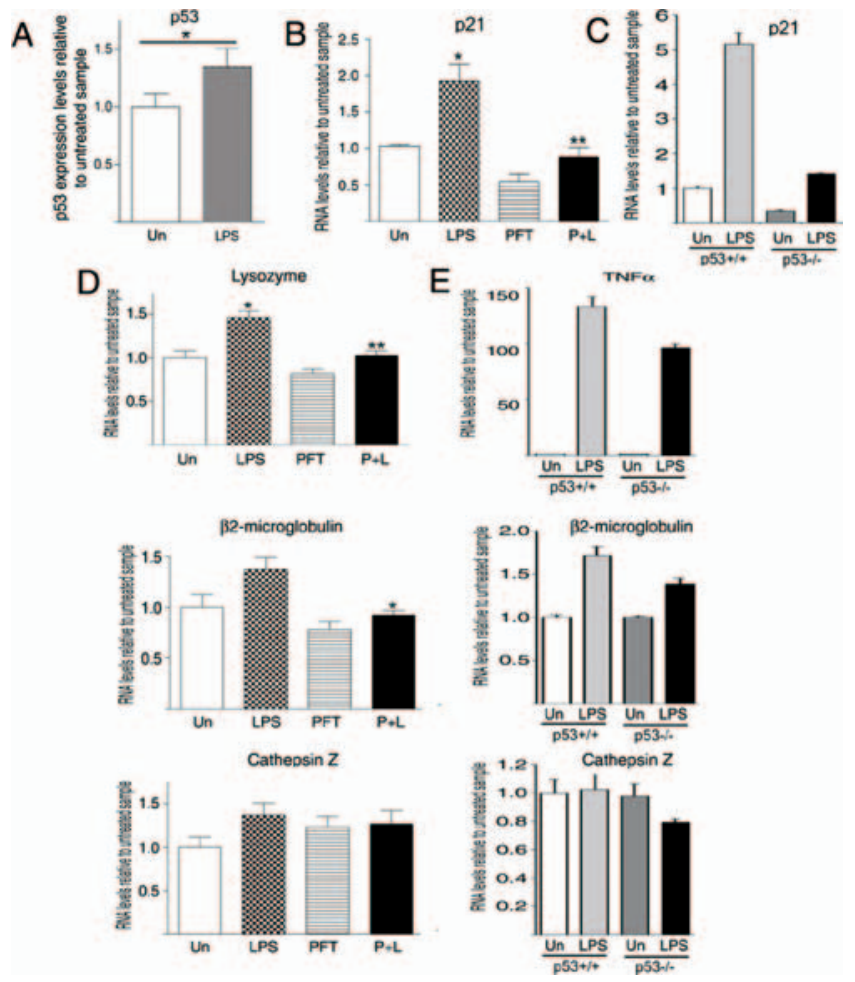

Figure 7. Pharmacological inhibition of p53-dependent transcriptional activity decreases the transcriptional activation induced by LPS in microglial cells. $A$, Quantitative real-time PCR of p53 mRNA levels in samples isolated from BV2 microglial cells either untreated (Un) or treated with $100 \mathrm{ng} / \mathrm{ml}$ LPS. * $p<0.01$ versus untreated cells. $\boldsymbol{B}$, Quantitative real-time PCR of the $\mathrm{p} 21$ mRNA levels in samples extracted from BV2 cells either untreated or treated with $100 \mathrm{ng} / \mathrm{ml}$ LPS alone (LPS), $20 \mu \mathrm{m}$ pifithrin- $\alpha$ alone, or cotreated for $6 \mathrm{~h} .{ }^{* *} p<0.001$ versus LPS-treated cells; ${ }^{*} p<0.01$ versus untreated cells. $C$, Real-time PCR of $p 21$ transcript levels measured in RNA samples from primary microglial cultures isolated from $p 53^{+/+}$and $p 53^{-/-}$mice and stimulated with LPS. D, Quantitative real-time PCR of the mRNA levels in samples isolated from BV2 cells as described in $\boldsymbol{B}$. Lysozyme, ${ }^{*} p<0.01$ versus untreated cells, ${ }^{* *} p<0.01$ versus LPS; $\beta 2$-microglobulin, ${ }^{*} p<0.05$ versus LPS. The levels of cathepsin $Z$ were not affected by pifithrin- $\alpha$. Bar graphs represent the mean \pm SEM of four independent experiments run in triplicate (ANOVA followed by Bonferroni's multiple comparison test). $\boldsymbol{E}$, Effect of LPS treatment on transcripts indicative of microglial cell activation. The bar graphs represent the results of quantitative real-time $P C R$ performed on RNA isolated from primary cultures of $p 53^{+/+}$and $p 53^{-1-}$ microglial cells stimulated with LPS. Note the lower level of microglial gene activation detected in $p 53^{-1-}$ cells and the similarity with the in vivo data in cuprizone-fed mice, shown in Figure 5. Un, Untreated; PFT, pifithrin- $\alpha ; \mathrm{P}+\mathrm{L}$, pifithrin- $\alpha$ plus LPS. Error bars indicate SEM.

microglial cells, which is independent of the effect on the oligodendrocytes. Indeed, systemic administration of pharmacological inhibitors of p53 (i.e., pifithrin- $\alpha$ ) to cuprizone-treated mice positively impacted the course of the disease, by decreasing microglial accumulation and gene expression even if started after the occurrence of oligodendroglial apoptosis. The effect of p53 on gene expression was also suggested by the results of the in vitro studies in LPS-stimulated primary microglial cultures and in the BV2 microglial cell line. In agreement with previous reports on the increased expression of $p 53$ in microglial cells in response to infectious or excitotoxic stimuli (Garden et al., 2004; Villapol et al., 2007), we have detected the upregulation of $p 53$ and of its downstream target gene $p 21$ in cultures stimulated with LPS and suggested that $\mathrm{p} 53$ functions as a modulator of the transcriptional response characteristic of activated microglia. Our results indicate lower levels of $\beta 2$-microglobulin levels in $p 53^{-1-}$ microglial cultures compared with controls, in response to the activating stimulus. Treatment of the BV2 cells with pifithrin- $\alpha$ similarly reduced the LPS-dependent activation of the microglial genes lysozyme and $\beta 2$-microglobulin. The effect of genetic ablation of $p 53$ or pharmacological treatment with pifithrin- $\alpha$ was selective because it did not affect the levels of cathepsin $Z$. Our results cannot determine whether the effect of p53 on microglial gene expression is direct or indirect, possibly by modulating additional components of the transcriptional network. In peripheral macrophages, for instance, p53 has been shown to inhibit cytokine expression (Komarova et al., 2005), by interfering with NF- $\kappa$ bdependent gene expression (Dijsselbloem et al., 2007). Although it is becoming increasingly evident that peripheral macrophages and resident microglial cells constitute two distinct populations (Melchior et al., 2006), our data do not address whether p53dependent regulation of gene expression might represent an additional difference between these two cell types. However, our results support a p53-mediated transcriptional response during microglial activation.

The role of microglia in demyelination is well established (Carson, 2002; Kim and de Vellis, 2005; Sanders and De Keyser, 2007), and the studies in the cuprizone model of demyelination (Hiremath et al., 1998; Pasquini et al., 2007) have provided support to the concept that microglial activation might contribute to oligodendrocytic demise and neuronal damage (Pasquini et al., 2007). These premises have led to the therapeutic use of the tetracycline derivative minocycline, an antibiotic with the ability to inhibit the inflammatory response by modulation of the microglial component (Yrjanheikki et al., 1998, 1999; Yong et al., 2004). Whereas this approach has proven to be effective in limiting the lesion size in response to cuprizone (Pasquini et al., 2007) and in experimental autoimmune encephalomyelitis models (Popovic et al., 2002), it is also clear that it has negatively impacted remyelination and repair (Kotter et al., 2001; Li et al., 2005). The negative effect of minocycline treatment on remyelination could be attributed to several potential reasons. One possibility is that minocycline exerts a dose-dependent inhibition of oligodendrocyte progenitor proliferation, thereby reducing the pool of cells that can form new myelin (Li et al., 2005). An alternative possibility is that minocycline reduces the production of important trophic factors (i.e., BDNF) from microglial cells, thereby affecting oligodendrocyte progenitor cell proliferation and differentiation (Dougherty et al., 2000; Du et al., 2003). Therefore, the general consensus is that it is important to limit microglial activation, without necessarily abolishing it, to provide a source of trophic support for the repair mechanism. Our study, using genetic or pharmacological inhibition of p53, suggests that transient inhibition of this transcription factor might provide multiple beneficial effects in demyelinating disorders consequent to oligodendrogliopathy and massive microglial infiltration. Systemic administration with pifithrin- $\alpha$, for instance, decreases the extent of myelin loss and microglial accumulation and selectively reduced the levels of cytotoxic microglial gene products (i.e., lysozyme) without affecting the expression of trophic genes (i.e., BDNF). An added beneficial effect of this treatment was the proliferative and differentiative effect on multipotential progenitors in the adult SVZ that resulted in an increased number of Sox2-positive cells and enhanced oligodendrogliogenesis at the expenses of astrogliogenesis. We have previously reported that cells cultured from the SVZ of $p 53^{-1-}$ mice have the ability to generate more $\mathrm{O} 4+$ oligodendrocytes than cells isolated from $p 53^{+/+}$siblings (Gil-Perotin et al., 2006). Although we cannot rule out cell-extrinsic mechanisms, our current study shows that treatment with pifithrin- $\alpha$ results in a remarkably similar phenotype.

In conclusion, we propose that pharmacological compounds 
with transient inhibitory activity on p53, should be further investigated as potential therapeutic agents for primary demyelination. The design of small peptides with the ability to inactivate transiently and possibly in a reversible manner p53 in a cell-specific manner is highly desirable to avoid the complications that sustained inactivation of p53 could have on lymphocyte apoptosis (Okuda et al., 2002) and tumorigenesis (Donehower et al., 1992; Donehower, 1996; Lozano, 2007).

\section{References}

Aboul-Enein F, Rauschka H, Kornek B, Stadelmann C, Stefferl A, Bruck W, Lucchinetti C, Schmidbauer M, Jellinger K, Lassmann H (2003) Preferential loss of myelin-associated glycoprotein reflects hypoxia-like white matter damage in stroke and inflammatory brain diseases. J Neuropathol Exp Neurol 62:25-33.

Barnett MH, Prineas JW (2004) Relapsing and remitting multiple sclerosis: pathology of the newly forming lesion. Ann Neurol 55:458-468.

Ben-Hur T, Rogister B, Murray K, Rougon G, Dubois-Dalcq M (1998) Growth and fate of PSA-NCAM + precursors of the postnatal brain. J Neurosci 18:5777-5788.

Billon N, Terrinoni A, Jolicoeur C, McCarthy A, Richardson WD, Melino G, Raff M (2004) Roles for p53 and p73 during oligodendrocyte development. Development 131:1211-1220.

Blasi E, Barluzzi R, Bocchini V, Mazzolla R, Bistoni F (1990) Immortalization of murine microglial cells by a v-raf/v-myc carrying retrovirus. J Neuroimmunol 27:229-237.

Carson MJ (2002) Microglia as liaisons between the immune and central nervous systems: functional implications for multiple sclerosis. Glia 40:218-231.

Culmsee C, Zhu X, Yu QS, Chan SL, Camandola S, Guo Z, Greig NH, Mattson MP (2001) A synthetic inhibitor of $\mathrm{p} 53$ protects neurons against death induced by ischemic and excitotoxic insults, and amyloid beta-peptide. J Neurochem 77:220-228.

Decker L, Avellana-Adalid V, Nait-Oumesmar B, Durbec P, Baron-Van Evercooren A (2000) Oligodendrocyte precursor migration and differentiation: combined effects of PSA residues, growth factors, and substrates. Mol Cell Neurosci 16:422-439.

Dijsselbloem N, Goriely S, Albarani V, Gerlo S, Francoz S, Marine JC, Goldman M, Haegeman G, Vanden Berghe W (2007) A critical role for $\mathrm{p} 53$ in the control of NF-kappaB-dependent gene expression in TLR4-stimulated dendritic cells exposed to Genistein. J Immunol 178:5048-5057.

Donehower LA (1996) The p53-deficient mouse: a model for basic and applied cancer studies. Semin Cancer Biol 7:269-278.

Donehower LA, Harvey M, Slagle BL, McArthur MJ, Montgomery Jr CA, Butel JS, Bradley A (1992) Mice deficient for p53 are developmentally normal but susceptible to spontaneous tumours. Nature 356:215-221.

Dougherty KD, Dreyfus CF, Black IB (2000) Brain-derived neurotrophic factor in astrocytes, oligodendrocytes, and microglia/macrophages after spinal cord injury. Neurobiol Dis 7:574-585.

Du Y, Fischer TZ, Lee LN, Lercher LD, Dreyfus CF (2003) Regionally specific effects of BDNF on oligodendrocytes. Dev Neurosci 25:116-126.

Garden GA, Guo W, Jayadev S, Tun C, Balcaitis S, Choi J, Montine TJ, Moller T, Morrison RS (2004) HIV associated neurodegeneration requires p53 in neurons and microglia. FASEB J 18:1141-1143.
Giaccia AJ, Kastan MB (1998) The complexity of p53 modulation: emerging patterns from divergent signals. Genes Dev 12:2973-2983.

Gil-Perotin S, Marin-Husstege M, Li J, Soriano-Navarro M, Zindy F, Roussel MF, Garcia-Verdugo JM, Casaccia-Bonnefil P (2006) Loss of p53 induces changes in the behavior of subventricular zone cells: implication for the genesis of glial tumors. J Neurosci 26:1107-1116.

Hiremath MM, Saito Y, Knapp GW, Ting JP, Suzuki K, Matsushima GK (1998) Microglial/macrophage accumulation during cuprizone-induced demyelination in C57BL/6 mice. J Neuroimmunol 92:38-49.

Jurevics H, Largent C, Hostettler J, Sammond DW, Matsushima GK, Kleindienst A, Toews AD, Morell P (2002) Alterations in metabolism and gene expression in brain regions during cuprizone-induced demyelination and remyelination. J Neurochem 82:126-136.

Kim SU, de Vellis J (2005) Microglia in health and disease. J Neurosci Res 81:302-313.

Komarova EA, Krivokrysenko V, Wang K, Neznanov N, Chernov MV, Komarov PG, Brennan ML, Golovkina TV, Rokhlin OW, Kuprash DV, Nedo- 
A
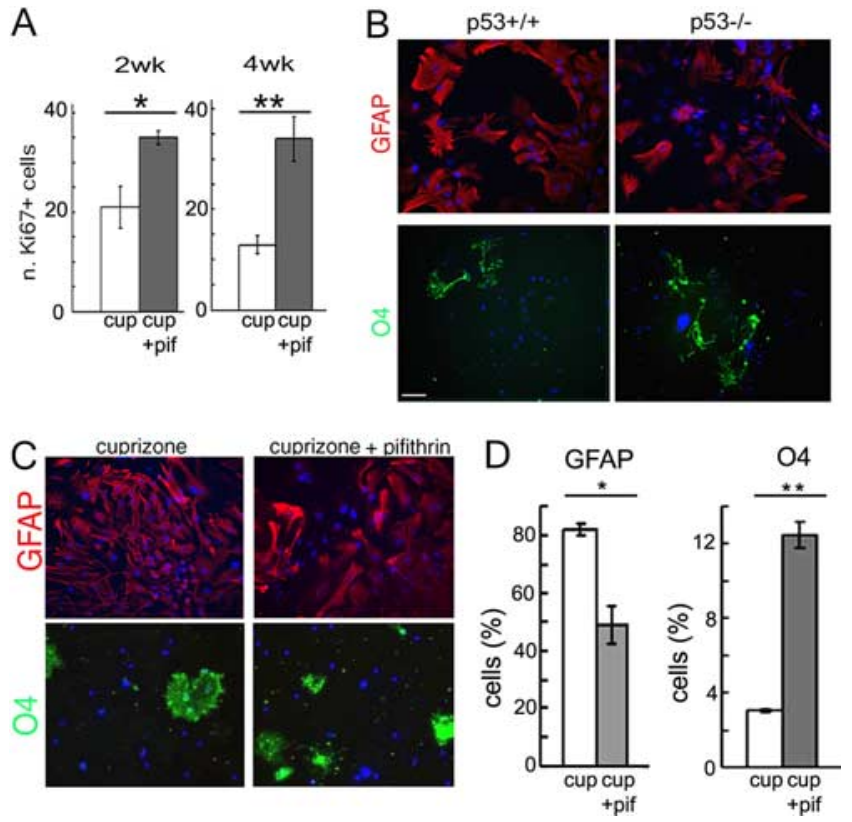

Figure 9. Pharmacological inhibition of p53-dependent transcriptional activity increases the proliferation and the generation of $04+$ cells from multipotential neural progenitors derived from the adult SVZ. A, Quantification of Ki67 + cells in the SVZ of mice that received only a $0.2 \%$ cuprizone (cup) diet or also received systemic administration of pifithrin- $\alpha$ (cup + pif) during the second (2wk) or fourth (4wk) week of cuprizone diet. ${ }^{*} p<0.05$; ${ }^{* *} p<0.01$. $\boldsymbol{B}$, Primary cultures of SVZ cells were obtained from adult $p 53^{+/+}$and $p 53^{-1-}$ mice, cultured as neurospheres, dissociated, exposed to cuprizone $(25 \mu \mathrm{m})$, and allowed to differentiate. Red, GFAP (astrocytes); green, 04 (oligodendrocytes); blue, DAPI as nuclear counterstain. Scale bar, $20 \mu \mathrm{m}$. C, SVZ cells isolated from adult $\mathrm{p} 53^{+/+}$mice were cultured as neurospheres, dissociated, exposed to cuprizone $(25 \mu \mathrm{m})$, and allowed to differentiate either in the absence (cuprizone) or presence of $20 \mu \mathrm{m}$ pifithrin- $\alpha$ (cuprizone + pifithrin) or $5 \mathrm{~d}$. Cultures were then stained with antibodies specific for GFAP (red, astrocytes), 04 (green, oligodendrocytes), and DAPI (blue) as nuclear counterstain. $\boldsymbol{D}$, Bar graphs indicate the percentage of immunoreactive cells relative to total DAPI+ cells. ${ }^{*} p<0.01 ;{ }^{* *} p<0.001$. Error bars indicate SEM.

spasov SA, Hazen SL, Feinstein E, Gudkov AV (2005) p53 is a suppressor of inflammatory response in mice. FASEB J 19:1030-1032.

Kondo T, Raff M (2004) Chromatin remodeling and histone modification in the conversion of oligodendrocyte precursors to neural stem cells. Genes Dev 18:2963-2972.

Kotter MR, Setzu A, Sim FJ, Van Rooijen N, Franklin RJ (2001) Macrophage depletion impairs oligodendrocyte remyelination following lysolecithininduced demyelination. Glia 35:204-212.

Kuhlmann T, Glas M, zum Bruch C, Mueller W, Weber A, Zipp F, Bruck W (2002) Investigation of bax, bcl-2, bcl-x and $\mathrm{p} 53$ gene polymorphisms in multiple sclerosis. J Neuroimmunol 129:154-160.

Ladiwala U, Li H, Antel JP, Nalbantoglu J (1999) p53 induction by tumor necrosis factor-alpha and involvement of p53 in cell death of human oligodendrocytes. J Neurochem 73:605-611.

Li WW, Setzu A, Zhao C, Franklin RJ (2005) Minocycline-mediated inhibition of microglia activation impairs oligodendrocyte progenitor cell responses and remyelination in a non-immune model of demyelination. J Neuroimmunol 158:58-66.

Lozano G (2007) The oncogenic roles of p53 mutants in mouse models. Curr Opin Genet Dev 17:66-70.

Lu DY, Tang CH, Liou HC, Teng CM, Jeng KC, Kuo SC, Lee FY, Fu WM (2007) YC-1 attenuates LPS-induced proinflammatory responses and activation of nuclear factor-kappaB in microglia. Br J Pharmacol 151:396405.

Lucchinetti C, Bruck W, Parisi J, Scheithauer B, Rodriguez M, Lassmann H (2000) Heterogeneity of multiple sclerosis lesions: implications for the pathogenesis of demyelination. Ann Neurol 47:707-717.
Matsushima GK, Morell P (2001) The neurotoxicant, cuprizone, as a model to study demyelination and remyelination in the central nervous system. Brain Pathol 11:107-116.

Melchior B, Puntambekar SS, Carson MJ (2006) Microglia and the control of autoreactive T cell responses. Neurochem Int 49:145-153.

Morell P, Barrett CV, Mason JL, Toews AD, Hostettler JD, Knapp GW, Matsushima GK (1998) Gene expression in brain during cuprizone-induced demyelination and remyelination. Mol Cell Neurosci 12:220-227.

Murtie JC, Zhou YX, Le TQ, Vana AC, Armstrong RC (2005) PDGF and FGF2 pathways regulate distinct oligodendrocyte lineage responses in experimental demyelination with spontaneous remyelination. Neurobiol Dis 19:171-182.

Nait-Oumesmar B, Decker L, Lachapelle F, Avellana-Adalid V, Bachelin C, Van Evercooren AB (1999) Progenitor cells of the adult mouse subventricular zone proliferate, migrate and differentiate into oligodendrocytes after demyelination. Eur J Neurosci 11:4357-4366.

Nait-Oumesmar B, Picard-Riera N, Kerninon C, Decker L, Seilhean D, Hoglinger GU, Hirsch EC, Reynolds R, Baron-Van Evercooren A (2007) Activation of the subventricular zone in multiple sclerosis: evidence for early glial progenitors. Proc Natl Acad Sci USA 104:4694-4699.

Okuda Y, Okuda M, Bernard CC (2002) The suppression of T cell apoptosis influences the severity of disease during the chronic phase but not the recovery from the acute phase of experimental autoimmune encephalomyelitis in mice. J Neuroimmunol 131:115-125.

Pasquini LA, Calatayud CA, Bertone Una AL, Millet V, Pasquini JM, Soto EF (2007) The neurotoxic effect of cuprizone on oligodendrocytes depends on the presence of pro-inflammatory cytokines secreted by microglia. Neurochem Res 32:279-292.

Picard-Riera N, Decker L, Delarasse C, Goude K, Nait-Oumesmar B, Liblau R, Pham-Dinh D, Evercooren AB (2002) Experimental autoimmune encephalomyelitis mobilizes neural progenitors from the subventricular zone to undergo oligodendrogenesis in adult mice. Proc Natl Acad Sci USA 99:13211-13216.

Popovic N, Schubart A, Goetz BD, Zhang SC, Linington C, Duncan ID (2002) Inhibition of autoimmune encephalomyelitis by a tetracycline. Ann Neurol 51:215-223.

Sanders P, De Keyser J (2007) Janus faces of microglia in multiple sclerosis. Brain Res Rev 54:274-285.

Stadelmann C, Ludwin S, Tabira T, Guseo A, Lucchinetti CF, Leel-Ossy L, Ordinario AT, Bruck W, Lassmann H (2005) Tissue preconditioning may explain concentric lesions in Balo's type of multiple sclerosis. Brain 128:979-987.

Trebst C, Heine S, Lienenklaus S, Lindner M, Baumgärtner W, Weiss S, Stangel M (2007) Lack of interferon-beta leads to accelerated remyelination in a toxic model of central nervous system demyelination. Acta Neuropathol 114:587-596.

Uberti D, Yavin E, Gil S, Ayasola KR, Goldfinger N, Rotter V (1999) Hydrogen peroxide induces nuclear translocation of p53 and apoptosis in cells of oligodendroglia origin. Brain Res Mol Brain Res 65:167-175.

Villapol S, Acarin L, Faiz M, Castellano B, Gonzalez B (2007) Distinct spatial and temporal activation of caspase pathways in neurons and glial cells after excitotoxic damage to the immature rat brain. J Neurosci Res 85:3545-3556.

Wosik K, Antel J, Kuhlmann T, Bruck W, Massie B, Nalbantoglu J (2003) Oligodendrocyte injury in multiple sclerosis: a role for p53. J Neurochem 85:635-644.

Yang B, Prayson RA (2000) Expression of Bax, Bcl-2, and P53 in progressive multifocal leukoencephalopathy. Mod Pathol 13:1115-1120.

Yong VW, Wells J, Giuliani F, Casha S, Power C, Metz LM (2004) The promise of minocycline in neurology. Lancet Neurol 3:744-751.

Yrjanheikki J, Keinanen R, Pellikka M, Hokfelt T, Koistinaho J (1998) Tetracyclines inhibit microglial activation and are neuroprotective in global brain ischemia. Proc Natl Acad Sci USA 95:15769-15774.

Yrjanheikki J, Tikka T, Keinanen R, Goldsteins G, Chan PH, Koistinaho J (1999) A tetracycline derivative, minocycline, reduces inflammation and protects against focal cerebral ischemia with a wide therapeutic window. Proc Natl Acad Sci USA 96:13496-13500. 